\title{
Gabriel Wackermann (sous la direction de), 2004, Géographie des risques
}

Paris, Ellipses, 501 p.

\section{Michel Deshaies}

\section{(2) OpenEdition}

\section{Journals}

Édition électronique

URL : http://journals.openedition.org/rge/2422

DOI : $10.4000 /$ rge. 2422

ISSN : 2108-6478

\section{Éditeur}

Association des géographes de l'Est

Édition imprimée

Date de publication : 1 juin 2003

ISSN : 0035-3213

\section{Référence électronique}

Michel Deshaies, «Gabriel Wackermann (sous la direction de), 2004, Géographie des risques », Revue Géographique de l'Est [En ligne], vol 43 / 3 | 2003, mis en ligne le 01 décembre 2010, consulté le 25 septembre 2020. URL : http://journals.openedition.org/rge/2422 ; DOI : https://doi.org/10.4000/rge. 2422

Ce document a été généré automatiquement le 25 septembre 2020

Tous droits réservés 


\section{Gabriel Wackermann (sous la direction de), 2004, Géographie des risques}

Paris, Ellipses, 501 p.

Michel Deshaies

\section{RÉFÉRENCE}

Gabriel Wackermann (sous la direction de), 2004, Géographie des risques, Paris, Ellipses, $501 \mathrm{p}$.

1 L'ouvrage dirigé par Gabriel Wackermann et consacré à la Géographie des risques dans le monde dépasse largement ce que l'on attend ordinairement d'un manuel destiné à la préparation des concours de recrutement de l'enseignement secondaire. En effet, la publication de cet ouvrage fait suite à la mise au programme de l'agrégation de géographie du thème des risques. Or, la richesse et la diversité des 21 contributions d'auteurs aboutissent à un volume de 501 pages constituant presque un traité de la géographie des risques qui, sans être exhaustif, couvre néanmoins l'essentiel des domaines concernés.

2 En effet, depuis une vingtaine d'années, la pression démographique croissante dans les pays en voie de développement et l'évolution de nos sociétés ont sensiblement accrus les risques auxquels des populations de plus en plus nombreuses sont exposées. La déstabilisation de certains milieux et le changement climatique qui semble se dessiner pourraient encore accentuer cette évolution à laquelle la géographie, science transversale d'analyse des systèmes et des interactions entre les sociétés et les milieux naturels, peut apporter sinon des solutions, du moins des clés de compréhension absolument essentielles. Les risques constituent donc un sujet d'étude à travers lequel la géographie peut facilement faire comprendre son utilité à la société. Cet ouvrage en constitue incontestablement la démonstration et devrait trouver un large public allant 
bien au-delà des candidats aux concours de recrutement de l'enseignement secondaire. On souhaite vivement que les aménageurs, les responsables politiques et administratifs auront la curiosité de consulter cet ouvrage, afin de nourrir leur réflexion et éviter que se répètent les erreurs dont les nombreuses catastrophes «naturelles» survenues au cours des quinze dernières années ont été trop souvent la tragique illustration.

3 Après une première partie introductive consacrée à définir la problématique générale (Gabriel Wackermann), en montrant les multiples facettes du risque et son ancienneté (Julien Mathieu) à travers l'analyse de deux catastrophes célèbres de l'Antiquité (l'Atlantide et Pompéi), l'ouvrage se décline en quatre autres parties différenciant les risques naturels ou à dominante naturelle des risques démographiques et anthropiques.

4 Les risques à dominante naturelle sont traités dans deux parties, avec d'une part les risques que l'on pourrait qualifier d'azonaux (sismiques, volcanisme, incendies et tempêtes affectant les forêts, risques en montagne et dans les milieux de bas plateaux et bassins) et d'autre part les risques à nette composante zonale (désertification, risques des milieux tropicaux à travers l'exemple caribéen, pays méditerranéens et risques naturels en Ile de France). On le voit, le tableau des risques naturels évoqués est assez large, quoiqu'il manque nous semble-t-il un domaine important, celui des littoraux avec le risque de submersion que le réchauffement de la planète et la montée du niveau marin rend de plus en plus menaçant pour certaines régions basses et atolls de l'océan Pacifique.

Les risques d'origine proprement humaine sont également traités dans deux parties. On distingue d'une part ceux liés à la croissance de la population, avec le mythe de la surpopulation qui fait l'objet d'une très intéressante analyse de Gérard-François Dumont, et les problèmes sanitaires, et d'autre part les risques liés essentiellement à la ville et à la société urbaine (risque technologique, risques sociétaux, risques patrimoniaux). Là encore, il nous semble qu'un autre thème aurait pu prendre place dans cette partie, celui des risques liés aux transports qui est d'une incontestable actualité. De la même façon les risques politiques ou géopolitiques, notamment ceux découlant du terrorisme, auraient pu également faire l'objet d'un dossier.

6 On voit immédiatement que dans ce domaine de la géographie du risque en perpétuelle évolution, il est impossible d'être exhaustif. Cet ouvrage est en tout cas incontestablement l'un des plus complets sur le sujet et devrait prendre place dans toute bonne bibliothèque de géographie.

\section{AUTEURS}

MICHEL DESHAIES

Université Nancy 2 